\title{
Impact of Personalised Patient Education on Bowel Preparation for Colonoscopy: Prospective Randomised Controlled Trial
}

\author{
Luís Elvas $^{a}$ Daniel Brito ${ }^{a}$ Miguel Areia ${ }^{a} b \quad$ Rita Carvalho ${ }^{a}$ Susana Alves ${ }^{a}$ \\ Sandra Saraiva ${ }^{a}$ Ana T. Cadime $^{a}$ \\ ${ }^{a}$ Department of Gastroenterology, Portuguese Oncology Institute, Coimbra, and ${ }^{b}$ CINTESIS - Center for Research in \\ Health Technologies and Information Systems, Faculty of Medicine, University of Porto, Porto, Portugal
}

\section{Keywords}

Colonoscopy · Bowel preparation · Patient education · Quality

\section{Abstract}

Background: Adequate bowel preparation is one of the most important quality factors of colonoscopy. Our goal was to analyse the impact of personalised patient education on bowel cleansing preparation for colonoscopy. Methods: We performed a single-blinded, single-centre, prospective randomised trial, where patients were either allocated to a control group, where they received some predefined oral and written information on bowel preparation from the gastroenterologist, or to an intervention group, where patients received additional personalised instructions for bowel preparation and diet from a nurse. The primary outcome was the quality of bowel preparation (Aronchick scale). Results: A total of 229 patients were randomised; 113 to the control group and 116 to the intervention group. In intention-totreat analysis, bowel preparation was adequate in 62\% (95\%
$\mathrm{Cl} 53-70)$ of colonoscopies in the intervention group and in $35 \%$ (95\% Cl $26-44)$ of colonoscopies in the control group $(p<0.001)$. The absolute risk reduction was $27 \%$, the relative risk was 1.77 , and the number needed to treat was 4 . Subgroup analysis showed a significant impact of personalised education in patients under 65 years ( 67 vs. $35 \% ; p<0.001$ ), in males ( 60 vs. $33 \% ; p=0.003$ ), in those with higher educational levels ( 68 vs. $37 \% ; p=0.002$ ), in those living in urban areas ( $68 \mathrm{vs.} 40 \% ; p=0.004$ ), and in those with previous colonoscopy ( 68 vs. $40 \% ; p=0.001$ ). Risk factors for inadequate preparation were: male gender $(\mathrm{OR}=2.1 ; 95 \% \mathrm{Cl} 1.1-4.1)$, diabetes mellitus $(\mathrm{OR}=3.8 ; 95 \% \mathrm{Cl} 1.2-11.6)$, chronic constipation $(\mathrm{OR}=3.7 ; 95 \% \mathrm{Cl} 1.7-8.2)$, absence of prior abdominal surgery $(\mathrm{OR}=2.2 ; 95 \% \mathrm{Cl} 1.2-4.1)$, and being in the control group (OR $=2.5 ; 95 \% \mathrm{Cl} 1.4-4.4)$. Conclusions: Personalised patient education on bowel preparation for colonoscopy significantly improved the quality of bowel preparation.

(c) 2016 Sociedade Portuguesa de Gastrenterologia Published by S. Karger AG, Basel

\section{KARGER}

E-Mail karger@karger.com www.karger.com/pjg
(C) 2016 Sociedade Portuguesa de Gastrenterologia Published by S. Karger AG, Basel Karger Open access

This article is licensed under the Creative Commons AttributionNonCommercial-NoDerivatives 4.0 International License (CC BYNC-ND) (http://www.karger.com/Services/OpenAccessLicense) Usage and distribution for commercial purposes as well as any distribution of modified material requires written permission.
Dr. Luís Elvas

Department of Gastroenterology, Portuguese Oncology Institute

Av. Bissaya Barreto, $\mathrm{n}^{\circ} 98$

PO-3000-075 Coimbra (Portugal)

E-Mail luisandreelvas@gmail.com 
Impacto do Ensino Personalizado na Preparação Intestinal para Colonoscopia: Estudo Prospetivo Controlado Randomizado

\section{Palavras Chave}

Colonoscopia · Preparação intestinal · Ensino do doente · Qualidade

\section{Resumo}

Introdução: Uma adequada preparação intestinal é um dos fatores de qualidade mais importantes de uma colonoscopia. O objetivo foi analisar o impacto do ensino personalizado na qualidade da preparação intestinal. Material e Métodos: Estudo prospetivo randomizado, cego para o endoscopista, num único centro hospitalar. Os doentes foram randomizados em 2 grupos: "controlo" receberam informação pré-definida sobre a preparação intestinal pelo gastrenterologista assistente; "intervenção" - após a consulta com gastrenterologista receberam informações personalizadas em consulta de enfermagem, com explicação pormenorizada da preparação e dieta. O outcome primário foi a qualidade da preparação intestinal (escala de Aronchick). Resultados: Randomizados 229 doentes, 113 no grupo "controlo" e 116 no "intervenção". As preparações foram consideradas "adequadas" em 62\% (95\% IC 53-70) das colonoscopias do grupo "intervenção" e em 35\% (95\% IC 26-44) do grupo "controlo" $(p=0.001)$. A redução de risco absoluto foi $27 \%$, risco relativo 1.77 e número necessário para tratar de 4 . A análise de subgrupos revelou um impacto mais significativo do ensino personalizado nos doentes até 65 anos ( 67 vs. $35 \%, p<0.001$ ), sexo masculino (60 vs. $33 \%, p=0.003$ ), maior grau de escolaridade (68 vs. $37 \%, p=0.002)$, residentes em meio urbano ( 68 vs. $40 \%, p=0.004$ ) e com colonoscopias prévias ( 68 vs. $40 \%, p=0.001$ ). Foram identificados como fatores de risco para má preparação: género masculino (OR $=2.1 ; 95 \%$ IC 1.1-4.1), diabetes mellitus $(\mathrm{OR}=3.8$; 95\% IC 1.2-11.6), obstipação (OR = 3.7; $95 \%$ IC 1.7-8.2), inexistência de cirurgia abdominal prévia (OR = 2.2; 95\% IC 1.2-4.1) e ausência de ensino personalizado $(\mathrm{OR}=2.5$; 95\% IC 1.4-4.4). Conclusão: O ensino personalizado da preparação intestinal para colonoscopia melhora significativamente a qualidade da preparação intestinal.

๑ 2016 Sociedade Portuguesa de Gastrenterologia Publicado por S. Karger AG, Basel

\section{Introduction}

Colonoscopy is the best procedure to evaluate the colon, allowing direct visualisation of mucosal abnormalities and performing mucosal biopsies and therapeutic procedures such as polypectomy. One of the most important quality criteria of colonoscopy is the adequacy of bowel preparation [1].

The rates of inadequate bowel preparation in published data are $20-25 \%[2,3]$. It leads to longer procedure times with increased difficulty in caecal intubation, decreased adenoma detection rate and shortening of followup intervals, which will increase the cost of colonoscopy $[1,4,5]$. Regarding follow-up intervals, a survey published in 2011 concluded that gastroenterologists provide broadly dissimilar recommendations for timing of follow-up colonoscopy when colon preparation is not ideal [6]. Another study showed that as there is some risk of missed lesions gastroenterologists tend to shorten followup intervals with fair or "intermediate" quality preparation [7]. However, a recent meta-analysis suggests that patients with "fair" preparation quality may be followed up at standard guideline-recommended surveillance intervals without significantly affecting quality as measured by the adenoma detection rate [8].

A great amount of data has been published on factors related to inadequate bowel preparation, such as male gender, constipation, drugs (antidepressants, opioids), previous colonic surgery, obesity, diabetes, inpatient status, neurologic diseases, and lower education levels [9-11].

After choosing the best preparation for their patient, one of the hardest challenges for the health care team is to provide correct and clear information to improve patient cooperation, while emphasising the importance of compliance to obtaining a good bowel cleansing quality. International guidelines have recently been published on this subject, suggesting that it is important to provide both oral and written instructions for all components of the colonoscopy preparation $[12,13]$. However, data have also been published reporting that many patients do not follow bowel cleaning instructions. A number of factors may contribute to this, such as patients who do not properly understand the instructions on leaflets or those who forget the explanations if the time interval between the appointment when instructions were given and colonoscopy is longer than 16 weeks [14-16].

Our clinical hypothesis was that, in patients undergoing colonoscopy, additional personalised patient instructions for bowel preparation and diet would improve the 
quality of bowel cleansing, compared with the cursory information usually given by the gastroenterologist at appointments and the leaflets handed out to patients.

Our main objective was to analyse the impact of that additional personalised patient education on the quality of bowel preparation for patients scheduled for outpatient colonoscopy by performing a single-blinded, randomised, controlled trial.

\section{Materials and Methods}

\section{Trial Design}

The present study reports a single-centre, prospective, endoscopist-blinded, randomised controlled trial. Patients enrolled in the study were allocated to one of two groups: a control group receiving verbal instructions for a 1-day diet without fibre, i.e., avoid soup, vegetables, fruits and seeds before colonoscopy, and written information from their attending gastroenterologist on the time to start the bowel preparation; and an intervention group, where patients received additional information from our nurses, with personalised diet modifications in terms of types of food according to patient preferences (examples of meals from an extensive list were provided). The length of the diet period was adjusted according to the patients' bowel habits (with an extra day of diet per usual day without bowel movements or previous abdominal surgeries) and any doubts on how to correctly take the bowel preparation were clarified. However, the diet for the intervention group is not different; it is just more detailed and is the result of a two-way exchange of information instead of one-way information given to the patient. After an appointment with the gastroenterologist, our department secretaries were responsible for the randomisation and allocation process (using computer-generated randomisation tables) and patients in the intervention group were directed to the nurse's office. The nursing logistics meant that at least 1 nurse needed to be available to talk to the patient for at least $15 \mathrm{~min}$ in a dedicated room; during working hours, they were also available to answer questions by phone, as needed (only $2 \%$ of patients called and each call lasted no more than $5 \mathrm{~min}$ ).

\section{Study Population}

Consecutive patients scheduled for an outpatient morning colonoscopy were invited to participate in the study, where the proposed bowel preparation would be $4 \mathrm{~L}$ of a polyethylene glycol (PEG)-based bowel preparation (PEG-4L) administered the previous afternoon. Patients were included if they were over 18 years old, presented an indication for colonoscopy and had no contraindication to the procedure or known allergy or intolerance to PEG solution. Exclusion criteria were: referral for polypectomy in patients with previous total colonoscopy and adequate bowel preparation, known colorectal cancer, previous intestinal surgery, inpatients, and sedation during the procedure. We excluded sedation procedures since we have a longer and quite variable waiting time for colonoscopy under sedation. We thus avoided a bias caused by the long period between the appointment with the gastroenterologist (and nurse) and the endoscopic procedure, which is a wellknown risk factor for inadequate bowel preparation (our waiting period for colonoscopies without sedation is just 2-4 weeks).
The study was performed at a single oncology centre, to which most patients with polyps or colonic neoplasia are referred and all colonoscopies were performed by 2 gastroenterologists with more than 10 years of experience in the procedure.

\section{Ethical Consideration}

Our study was approved by the institutional ethics committee of our hospital and data collection started after approval has been given, but there was no public, prospective registration of the trial. All patients signed an informed consent and there was no financial support for this study.

\section{Procedure}

All colonoscopies were performed from 9 a.m. to 1 p.m. after bowel preparation with $4 \mathrm{~L}$ of PEG taken on the previous afternoon from 4 to $8 \mathrm{p}$.m. Every patient received predefined verbal and written instructions on how to prepare for a colonoscopy from their attending gastroenterologist, which included a low-fibre diet on the day before the procedure until the beginning of the preparation. The preparation consisted of 1 sachet of PEG in $1 \mathrm{~L}$ of water (total of $4 \mathrm{~L}$ ) and drinking 1 glass every 10-15 min to complete the preparation in $4 \mathrm{~h}$. No additional laxatives were allowed during the bowel preparation. Then, those allocated to the intervention group met with one of our nurses to receive additional information (as explained above). This appointment lasted around $20 \mathrm{~min}$. A telephone number was available to every patient in the intervention group for additional information.

At the end of the procedure, patients were asked to complete a questionnaire to provide information on their age, education level, residence, previous colonoscopies and medical history on bowel habits, diabetes mellitus status and previous abdominal surgery. Other data included tolerance to bowel preparation, quality of the provided information and willingness to repeat a colonoscopy.

\section{Outcomes}

The primary outcome was the quality of bowel preparation according to the modified Aronchick bowel preparation scale split into adequate and inadequate (Table 1) [17]. Preparation classification was recorded by the gastroenterologist performing the colonoscopy. This specific scale was chosen over other scales because it is simpler and faster to report. Washing and flushing was allowed during the procedures, but the Aronchick scale classification was done before that. Adequate preparations included excellent and good classifications that would not change the follow-up colonoscopy, while inadequate preparations would include fair, poor or inadequate classifications according to the Aronchick scale. Fair preparations would fall into the inadequate category because of the known differences in recommendations for timing a follow-up colonoscopy that this might imply.

Secondary outcomes were: to determine which clinical features were related to inadequate bowel preparation, such as age, gender, education, previous colonoscopy or previous abdominal surgery; to identify who could potentially benefit the most from our intervention; and to compare the quality of preparations in both groups between "poor" and "non-poor" preparations (by including the fair preparations in the "non-poor" group).

Before the beginning of this study, both endoscopists performed and classified 20 real-life bowel preparations through simultaneous in-person observation of 20 colonoscopies, which 
Table 1. Modified Aronchick bowel preparation scale

\begin{tabular}{ll}
\hline Classification & Quality of bowel preparation \\
\hline Excellent & $\begin{array}{l}\text { Small amount of clear liquid with clear mucosa } \\
\text { seen; more than 95\% mucosa seen }\end{array}$ \\
\hline Good & $\begin{array}{l}\text { Small amount of turbid fluid without faeces, not } \\
\text { interfering with examination; more than 90\% } \\
\text { mucosa seen }\end{array}$ \\
\hline Fair & $\begin{array}{l}\text { Moderate amount of stool that can be cleared } \\
\text { with suctioning to permit adequate evaluation of } \\
\text { entire colonic mucosa; more than 90\% mucosa } \\
\text { seen }\end{array}$ \\
\hline Poor & $\begin{array}{l}\text { Inadequate but examination completed; enough } \\
\text { faeces or turbid fluid to prevent a reliable } \\
\text { examination; less than 90\% mucosa seen }\end{array}$ \\
\hline Inadequate & $\begin{array}{l}\text { Re-preparation required; large amount of faecal } \\
\text { residue precludes a complete examination }\end{array}$ \\
\hline
\end{tabular}

were then classified individually according to the Aronchick scale to calculate the interobserver correlation.

There were no changes to the trial outcomes after the study commenced.

\section{Sample Size Calculation}

We conducted a preliminary analysis based on our historical database to determine our rate of inadequate preparations and allow any adjustments to the sample size calculation, if needed. Our results showed an inadequate preparation rate of $60 \%$. Based on these results, if we consider a one-third improvement in the quality of bowel preparation, from 60 to $40 \%$ of inadequate preparations, and assuming an $80 \%$ power and a 2 -sided $5 \%$ significance level, a sample size of 97 patients for each group would be required to detect statistically significant differences between groups. To account for around $10 \%$ of losses during the recruitment, the target estimated number per group should be 108 . No stopping guidelines were predefined and an interim analysis half-way through the inclusion process confirmed a $60 \%$ rate of inadequate preparations in the control group versus $40 \%$ in the intervention group [18].

\section{Randomisation}

The random allocation sequence was computer-generated by a doctor not performing the inclusion or the intervention. Patients were enrolled by the 2 gastroenterologists who would perform the colonoscopies and evaluate bowel preparation, and they were blinded to the group allocation. A table of sequentially generated numbers was given to the secretary who would tell the patient to which group they were assigned. The secretary was instructed to comply strictly with the allocation order and the table was never available to the gastroenterologists who enrolled the patients. The administrative and nursing staff knew about the assignment to groups but played no part in evaluating the outcomes. Patients were not blinded but they were strictly instructed not to reveal their group assignment to their doctor. All other issues related to the interventions within the groups were exactly the same, such as type of bowel preparation, schedule of bowel preparation and schedule of the colonoscopy.

\section{Statistical Analysis}

Statistical analysis was performed with SPSS v.20 (IBM Corporation, New York, NY, USA), using the Student $t$ test for continuous and the $\chi^{2}$ test for categorical variables. Univariate and multivariate logistic regression analyses were performed to identify risk factors for inadequate preparation. The significance level was set at a 2 -sided $5 \%$.

Cohen's $\kappa$ coefficient was used for grading the interobserver agreement (strength of agreement considered as follows: 0.01-0.2 slight, 0.21-0.4 fair, 0.41-0.6 moderate, 0.61-0.8 substantial, and $0.81-1.0$ almost perfect) [19].

Absolute risk reduction was calculated by the difference between the absolute risk of the control group minus the absolute risk of the intervention group; the relative risk by the division of the absolute risk of the treatment group versus the absolute risk of the control group; and the number needed to treat was calculated by dividing 1 by the absolute risk reduction.

\section{Results}

During the study period, 342 patients were referred to our department for non-sedation colonoscopy and 113 were excluded because of previous colorectal surgery $(n=11)$, referral for polypectomy with previous total colonoscopy $(n=72)$, already diagnosed colorectal cancer $(n=6)$ and due to refusal in performing bowel preparation with PEG-4L $(n=24)$ (Fig. 1$)$. A total of 229 patients were randomised; 116 to the intervention group and 113 to the control group. Two patients from the intervention group did not have a complete colonoscopy (due to pain and a stenotic lesion). The control group included 4 patients with incomplete colonoscopy and 9 who took a bowel preparation product other than PEG-4L. The main outcome was analysed on an intention-to-treat analysis and instead of excluding these patients from our analysis we classified their preparation quality as "not-applicable" (Table 2) and decided to include them in the inadequate category.

Patients were recruited and randomised from 2008 to 2011 and follow-up ended a month after the inclusion of the last patient, by which time the respective colonoscopy had been performed. The trial only ended after the inclusion of the necessary patients.

The patients' characteristics are presented in Table 3. Mean age of both groups was 60 years, with a slight male predominance (54.2\%). The data for the control and intervention groups were, respectively: education level higher than primary school - 46 versus $44 \%$; diabetes mellitus - 11 versus $7 \%$; chronic constipation - 19 versus 


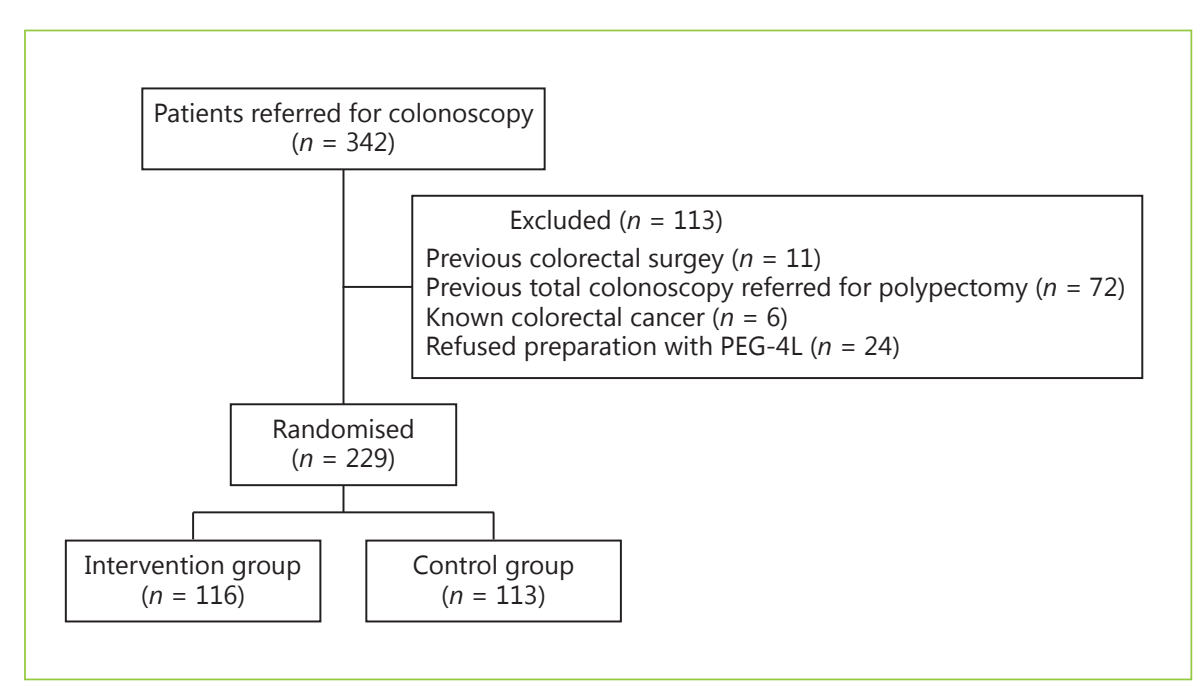

Fig. 1. Study flowchart.

Table 2. Main results on quality of bowel preparation

\begin{tabular}{llll}
\hline $\begin{array}{l}\text { Quality of bowel } \\
\text { preparation }\end{array}$ & $\begin{array}{l}\text { Control, } \\
n(\%) \\
(n=113)\end{array}$ & $\begin{array}{l}\text { Intervention, } \\
n(\%) \\
(n=116)\end{array}$ & $p$ \\
\hline $\begin{array}{l}\text { Adequate } \\
\text { Excellent }\end{array}$ & $24(21)$ & $48(41)$ & \\
Good & $16(14)$ & $24(21)$ & \\
\hline Subtotal & $40(35)$ & $72(62)^{\mathrm{a}}$ & $<0.001^{\mathrm{a}}$ \\
\hline $\begin{array}{l}\text { Inadequate } \\
\text { Fair }\end{array}$ & $38(34)$ & $38(33)$ & \\
Poor & $22(20)$ & $4(3.4)$ & \\
Inadequate & $0(0)$ & $0(0)$ & \\
Not applicable & $13(12)$ & $2(1.7)$ & $<0.001^{\mathrm{a}}$ \\
\hline Subtotal & $73(65)$ & $44(38)^{\mathrm{a}}$ & \\
\hline
\end{tabular}

Main outcome for quality of the bowel preparation in an intention-to-treat analysis. Patients in the control group received a predefined 1-day diet and PEG-4L bowel preparation while patients in the intervention group received further personalised instructions from the nursing staff. ${ }^{a} \chi^{2}$ test between subtotal results (adequate vs. inadequate). ${ }^{b}$ Patients with incomplete colonoscopies or bowel preparation with a product other than PEG$4 \mathrm{~L}$.

$25 \%$; previous abdominal surgery - 35 versus $49 \%$; and previous colonoscopy -72 versus $55 \%$.

By the end of the procedure, all the patients included in the study considered the information they were given on bowel preparation was good enough and just 1 patient $(<1 \%)$ in the intervention group complained that the per-
Table 3. Patients' characteristics

\begin{tabular}{lll}
\hline Characteristic & $\begin{array}{l}\text { Control } \\
(n=113)\end{array}$ & $\begin{array}{l}\text { Intervention } \\
(n=116)\end{array}$ \\
\hline $\begin{array}{l}\text { Age, mean } \pm \text { SD, years } \\
\text { Gender }\end{array}$ & $59 \pm 11$ & $60 \pm 13$ \\
$\quad$ Male & $66(58 \%)$ & $59(51 \%)$ \\
$\quad$ Female & $47(42 \%)$ & $57(49 \%)$ \\
Grade of education & & \\
$\quad$ Primary school or lower & $61(54 \%)$ & $65(56 \%)$ \\
$\quad$ Higher than primary school & $52(46 \%)$ & $51(44 \%)$ \\
Living area & $51(45 \%)$ & $69(60 \%)$ \\
$\quad$ Urban & $62(55 \%)$ & $47(40 \%)$ \\
$\quad$ Rural & $12(11 \%)$ & $8(7 \%)$ \\
Medical history & $22(19 \%)$ & $29(25 \%)$ \\
$\quad \begin{array}{l}\text { Diabetes mellitus } \\
\text { Chronic constipation }\end{array}$ & $40(35 \%)$ & $57(49 \%)$ \\
$\quad$ Previous abdominal surgery & $81(72 \%)$ & $64(55 \%)$ \\
Previous colonoscopy & & \\
\hline
\end{tabular}

SD, standard deviation.

sonalised education was not helpful. Regarding patient tolerance to the preparation product, there were no significant differences between the control and intervention groups ("well tolerated" in 57 vs. $47 \%, p=0.16$ ). The majority stated that colonoscopy was easier than they expected ( 86 vs. $84 \%, p=0.71$ ) and that they would repeat the procedure without sedation in the future ( 97 vs. $96 \%$, $p=0.59$ ).

Cohen's $\kappa$ coefficient of interobserver agreement for the grading of bowel preparation between the two gastro- 
Table 4. Risk factors associated with inadequate preparation in univariate and multivariate analysis

\begin{tabular}{|c|c|c|c|c|}
\hline $\begin{array}{l}\text { Characteristic } \\
(n=214)\end{array}$ & $\begin{array}{l}\text { Inadequate } \\
\text { preparation, } n(\%)\end{array}$ & $\begin{array}{l}\text { Adequate } \\
\text { preparation, } n(\%)\end{array}$ & $\begin{array}{l}\text { Univariate } \\
\text { analysis, } p\end{array}$ & $\begin{array}{l}\text { Multivariate } \\
\text { analysis }^{\mathrm{a}}, p\end{array}$ \\
\hline Age & & & 0.949 & \\
\hline$<65$ years & $66(48)$ & $72(52)$ & & \\
\hline$\geq 65$ years & $36(47)$ & $40(53)$ & & \\
\hline Gender & & & 0.066 & 0.024 \\
\hline Male & $62(53)$ & $54(47)$ & & \\
\hline Female & $40(41)$ & $58(59)$ & & \\
\hline Grade of education & & & 0.835 & \\
\hline Primary school or lower & $57(48)$ & $61(52)$ & & \\
\hline Higher than primary school & $45(47)$ & $51(53)$ & & \\
\hline Living area & & & 0.183 & \\
\hline Urban & $49(43)$ & $64(57)$ & & \\
\hline Rural & $53(52)$ & $48(48)$ & & \\
\hline Diabetes mellitus & & & 0.023 & 0.019 \\
\hline No & $88(45)$ & $107(55)$ & & \\
\hline Yes & $14(74)$ & $5(26)$ & & \\
\hline Chronic constipation & & & 0.066 & 0.001 \\
\hline No & $74(44)$ & $93(56)$ & & \\
\hline Yes & $28(60)$ & $19(40)$ & & \\
\hline Previous abdominal surgery & & & 0.010 & 0.014 \\
\hline No & $68(55)$ & $55(45)$ & & \\
\hline Yes & $34(37)$ & $57(63)$ & & \\
\hline Previous colonoscopy & & & 0.703 & \\
\hline No & 39 (49) & $40(51)$ & & \\
\hline Yes & $63(47)$ & $72(53)$ & & \\
\hline Intervention & & & 0.001 & 0.003 \\
\hline No & $60(60)$ & $40(40)$ & & \\
\hline Yes & $42(31)$ & $72(69)$ & & \\
\hline
\end{tabular}

a Multivariate analysis controlled for gender, living area, diabetes, constipation, previous abdominal surgery and intervention (univariate analysis cut-off: $p<0.25$ ).

enterologists was 1.0 in the pre-test before starting the study.

The final intention-to-treat analysis included $116 \mathrm{pa}-$ tients in the intervention group and 113 patients in the control group. Bowel preparation was graded as adequate (good or excellent) in 35\% (95\% CI 26-44) of colonoscopies of the control group patients and in 62\% (95\% CI 53-70) of the intervention group, which was statistically significant $(p<0.001)$ (Table 2). The absolute risk reduction achieved with the intervention was $27 \%$, with a relative risk of 1.77 and a number needed to treat of 4 . Per-protocol analysis showed that preparation was good or excellent in 40\% (95\% CI 30-50) of colonoscopies of the control group patients and in 63\% (95\% CI 54-72) of the intervention group, which was also statistically significant $(p<0.001)$.

There were also major differences in the number of poor bowel preparations, with $22 \%(14-30 \%)$ in the con- trol group versus $3.5 \%(0.2-6.8 \%)$ in the intervention group $(p<0.001)$.

A subgroup analysis of our pre-specified secondary outcomes showed a tendency towards improved preparation quality in females assigned to the intervention group and a statistically significant improvement in males (33\% adequate preparations in control group vs. $60 \%$ in intervention group, $p=0.003$ ).

Concerning age groups, personalised education proved to be beneficial for patients younger than 65 (35 vs. $67 \%, p<0.001$ ), but not for older patients.

The quality of bowel preparation was also improved in the intervention group in individuals educated beyond primary school level ( $37 \mathrm{vs.} 68 \%, p=0.002)$; there was also an improvement in those with lower education levels, although it was not significant ( 43 vs. $59 \%, p=0.07$ ). 
The quality of bowel preparation of patients living in urban areas was also improved (40 vs. $68 \%, p=0.004$ ) as well as in those who had already had a colonoscopy in the past ( 40 vs. $68 \%, p=0.001$ ); we found no significant differences for those living in rural areas (40 vs. $56 \%, p=$ 0.10 ) or undergoing their first colonoscopy (39 vs. $57 \%$, $p=0.14$ ). Regarding the patients' medical history, our results indicate an improvement in patients with chronic constipation and previous abdominal surgery, although without statistical significance ( 26 vs. $50 \%, p=0.104$ and 57 vs. $66 \%, p=0.392$, respectively). In our population of diabetic patients $(n=19)$, there was no difference in bowel preparation quality between the groups.

The quality of bowel preparation in our study was adequate in 112 patients (52\%) and inadequate in 102 patients (48\%). Risk factors for inadequate preparation were identified through multivariate logistic regression analysis and those with statistical significance $(p<0.05)$ were (Table 4): male gender $(\mathrm{OR}=2.1 ; 95 \%$ CI 1.1-4.1, $p=$ $0.024)$, diabetes mellitus $(\mathrm{OR}=3.8 ; 95 \% \mathrm{CI} 1.2-11.6, p=$ $0.019)$, chronic constipation $(\mathrm{OR}=3.7$; $95 \%$ CI $1.7-8.2$, $p=0.001)$, absence of prior abdominal surgery $(\mathrm{OR}=2.2$; $95 \%$ CI 1.2-4.1, $p=0.014$ ), and being in the control group $(\mathrm{OR}=2.5$; 95\% CI 1.4-4.4, $p=0.003)$. There was no relevant harm or unintended effects in either group.

\section{Discussion}

The primary aim of this study was to assess the effect of personalised patient education on the quality of bowel preparation for colonoscopy. We found that it significantly improved adequate preparations (good and excellent) in outpatients undergoing colonoscopy from $35 \%$ in the control group to $62 \%$ in the intervention group $(p=$ $0.001)$. This $27 \%$ risk reduction obtained with the intervention provides a number needed to treat of only 4 . These results highlight the importance of explaining bowel preparation information as clearly as possible to our patients and of being available to answer any queries instead of making a couple of predefined statements and giving them a few leaflets to read at home. In the subgroup analysis, we reported that personalised education had more impact on younger patients and males. We believe that these results could indicate that these two groups are less concerned with health problems. Here, the intervention could be effective at pointing out the benefits of adequate bowel preparation. Other groups that significantly benefited from personalised education were those with higher education levels, people living in urban areas and patients who had already undergone a colonoscopy in the past. One explanation for such benefit could be that these patients were unduly confident about their knowledge and the easiness of the procedure, and therefore failed to read the instructions carefully.

Overall, almost $48 \%$ of the patients had "fair" or "poor" bowel preparation. Although this might seem like a very high inadequate preparation rate, we should emphasise that this is explained by how we split our variable. This should not be a concern when interpreting our results because, if we look at the rates of "non-poor" preparations, we are clearly within the values of published data (where most "fair" preparations are considered adequate) - 69\% in the control group and $95 \%$ in the intervention group.

As our results bear out, one of the risk factors identified by logistic regression was the lack of patient education, but 4 other risk factors were also identified. Male gender had worse bowel preparation, which is similar to the findings of Fatima et al. [20], although other authors have not identified those differences [16, 21]. Diabetes mellitus and constipation were also risk factors for inadequate bowel preparation; this has been reported by other authors [9-11] and reflects the abnormal intestinal motility of these patients. Those without previous abdominal surgery also had worse bowel preparation. Patients with previous surgery may have more concerns about their health and be more aware of the importance of adequate colonic preparation.

One of the main concerns is the cost of this intervention. If we have to hire a nurse to perform this task, our costs will definitely increase. However, some departments could be able to reorganise staff tasks and have one nurse available without spending more; also, although we did not perform a cost-effectiveness analysis, if this intervention could help reduce repeat procedures, the decrease in the final cost might offset the money spent on new staff.

Some authors have reported the same outcome with different interventions, such as a 10-min physician-delivered education session [22], a new visual aid with cartoons [23], a booklet based on previous questionnaires answered by patients [24], a re-education phone call on the day before colonoscopy [25] and educational videos $[5,26]$. Two studies had different outcomes: Calderwood et al. [27] used a visual aid in their intervention group and Modi et al. [15] applied a questionnaire and reviewed and explained the incorrect answers, but neither could find significant differences in bowel preparation between the two groups. We recognise that some of these alternatives might be less expensive.
Elvas/Brito/Areia/Carvalho/Alves/ Saraiva/Cadime 
It is our opinion that future research should be directed at comparing these strategies, not only for their effectiveness but for their cost, too, and at comparing sameday and split-dose preparation regimens.

We believe that our trial is easily reproducible in medical centres around the world if nursing staff are available to provide patient education and provided that the bowel preparation product used is recommended by international guidelines $[12,13]$.

However, it has some limitations. Different bowel preparation protocols and regimens were not tested in our trial and the fact that we did not use a split-dose preparation, which decreases the rate of inadequate preparations compared to day-before preparation [28, 29], could have led to an increased effect of the intervention. We acknowledge that including the "fair" preparations in the "adequate" group could have had the same effect. We decided to use the Aronchick scale because it was the most common scale used by the time our study began, but it has meanwhile been reported that it is less well validated than the Boston scale and has shown inferior interobserver agreement than other scales [30] (nonetheless, our interobserver agreement was excellent). We also did not evaluate the impact of bowel preparation improvement on the duration of the procedure, adenoma detection rate (as most of our colonoscopies were scheduled for polypectomy, not screening), or cost. We do not report the patients' body mass index, which can influence the quality of bowel preparation. The random allocation sequence was not concealed in containers, which could explain some differences between the groups, despite randomisation, and the trial was not registered in a public domain.

In conclusion, our study is one of a few on this subject and clearly demonstrates the benefit of personalised patient education to the quality of bowel preparation, which is in accordance with a recently published meta-analysis [31]. We believe that better bowel preparation was a result of better compliance and cooperation from patients, along with improved understanding of the bowel preparation used. The ideal scenario would be to provide personalised education on bowel preparation to all patients. However, since this is not always possible because of personnel and budget constraints, it is important to assess our patients correctly and select those who can derive most benefit from this intervention.

\section{Acknowledgments}

The authors would like to thank the department nurses (Conceição Craveiro, Cristina França, Ana Ferreira, Marina Pedrosa, and Rita Alves) for their important contribution to this trial.

\section{Statement of Ethics}

Protection of Human and Animal Subjects

The authors declare that no experiments were performed on humans or animals for this study.

\section{Confidentiality of Data}

The authors declare that they have followed the protocols of their work centre on the publication of patient data.

Right to Privacy and Informed Consent

The authors have obtained the written informed consent of the patients or subjects mentioned in the article. The corresponding author is in possession of this document.

\section{Disclosure Statement}

The authors received no specific funding for this study and have no conflicts of interest to declare.
References

Impact of Patient Education on Bowel Preparation
1 Rembacken B, Hassan C, Riemann JF, Chilton A, Rutter M, Dumonceau JM, et al: Quality in screening colonoscopy: position statement of the European Society of Gastrointestinal Endoscopy (ESGE). Endoscopy 2012;44: 957-968.

2 Harewood GC, Sharma VK, de Garmo P: Impact of colonoscopy preparation quality on detection of suspected colonic neoplasia. Gastrointest Endosc 2003;58:76-79.

3 Froehlich F, Wietlisbach V, Gonvers JJ, Burnand B, Vader JP: Impact of colonic cleansing on quality and diagnostic yield of colonoscopy: the European Panel of Appropriateness of Gastrointestinal Endoscopy European multicenter study. Gastrointest Endosc 2005;61:378-384.
4 Rex DK, Imperiale TF, Latinovich DR, Bratcher LL: Impact of bowel preparation on efficiency and cost of colonoscopy. Am J Gastroenterol 2002;97:1696-1700.

5 Hsueh FC, Wang HC, Sun CA, Tseng CC, Han TC, Hsiao SM, et al: The effect of different patient education methods on quality of bowel cleanliness in outpatients receiving colonoscopy examination. Appl Nurs Res 2014;27:e1-e5.

6 Larsen M, Hills N, Terdiman J: The impact of the quality of colon preparation on follow-up colonoscopy recommendations. Am J Gastroenterol 2011;106:2058-2062. 
7 Ben-Horin S, Bar-Meir S, Avidan B: The impact of colon cleanliness assessment on endoscopists' recommendations for follow-up colonoscopy. Am J Gastroenterol 2007;102: 2680-2685.

8 Clark BT, Rustagi T, Laine L: What level of bowel prep quality requires early repeat colonoscopy: systematic review and meta-analysis of the impact of preparation quality on adenoma detection rate. Am J Gastroenterol 2014;109:1714-1723; quiz 1724.

9 Hautefeuille G, Lapuelle J, Chaussade S, Ponchon T, Molard BR, Coulom P, et al: Factors related to bowel cleansing failure before colonoscopy: results of the PACOME study. United European Gastroenterol J 2014;2:22-29.

10 Ness RM, Manam R, Hoen H, Chalasani N: Predictors of inadequate bowel preparation for colonoscopy. Am J Gastroenterol 2001;96: 1797-1802.

11 Rex DK: Optimal bowel preparation - a practical guide for clinicians. Nat Rev Gastroenterol Hepatol 2014;11:419-425.

12 Hassan C, Bretthauer M, Kaminski MF, Polkowski M, Rembacken B, Saunders B, et al: Bowel preparation for colonoscopy: European Society of Gastrointestinal Endoscopy (ESGE) guideline. Endoscopy 2013;45:142150.

13 Johnson DA, Barkun AN, Cohen LB, Dominitz JA, Kaltenbach T, Martel M, et al: Optimizing adequacy of bowel cleansing for colonoscopy: recommendations from the US multi-society task force on colorectal cancer. Gastrointest Endosc 2014;80:543-562.

14 Chan WK, Saravanan A, Manikam J, Goh KL, Mahadeva S: Appointment waiting times and education level influence the quality of bowel preparation in adult patients undergoing colonoscopy. BMC Gastroenterol 2011;11:86.
15 Modi C, Depasquale JR, Digiacomo WS, Malinowski JE, Engelhardt K, Shaikh SN, et al: Impact of patient education on quality of bowel preparation in outpatient colonoscopies. Qual Prim Care 2009;17:397-404.

16 Nguyen DL, Wieland M: Risk factors predictive of poor quality preparation during average risk colonoscopy screening: the importance of health literacy. J Gastrointestin Liver Dis 2010;19:369-372.

17 Aronchick CA, Lipshutz WH, Wright SH, Dufrayne F, Bergman G: A novel tableted purgative for colonoscopic preparation: efficacy and safety comparisons with Colyte and Fleet Phospho-Soda. Gastrointest Endosc 2000;52:346-352.

18 Carvalho R, Brito D, Areia M, Saraiva S, Catré A, Cadime AT, et al: Randomized clinical trial to analyze the impact of personal education on bowel preparation for colonoscopy - preliminary results. GE Port J Gastroenterol 2012;19:7.

19 Bland JM, Altman DG: Statistical methods for assessing agreement between two methods of clinical measurement. Lancet 1986;1:307310 .

20 Fatima H, Johnson CS, Rex DK: Patients' description of rectal effluent and quality of bowel preparation at colonoscopy. Gastrointest Endosc 2010;71:1244-1252 e2.

21 Wu KL, Rayner CK, Chuah SK, Chiu KW, Lu CC, Chiu YC: Impact of low-residue diet on bowel preparation for colonoscopy. Dis Colon Rectum 2011;54:107-112.

22 Shieh TY, Chen MJ, Chang CW, Hung CY, $\mathrm{Hu} \mathrm{KC}$, Kuo YC, et al: Effect of physician-delivered patient education on the quality of bowel preparation for screening colonoscopy. Gastroenterol Res Pract 2013;2013:570180.

23 Tae JW, Lee JC, Hong SJ, Han JP, Lee YH, Chung JH, et al: Impact of patient education with cartoon visual aids on the quality of bowel preparation for colonoscopy. Gastrointest Endosc 2012;76:804-811.
24 Spiegel BM, Talley J, Shekelle P, Agarwal N, Snyder B, Bolus R, et al: Development and validation of a novel patient educational booklet to enhance colonoscopy preparation. Am J Gastroenterol 2011;106:875-883.

25 Liu X, Luo H, Zhang L, Leung FW, Liu Z, Wang X, et al: Telephone-based re-education on the day before colonoscopy improves the quality of bowel preparation and the polyp detection rate: a prospective, colonoscopistblinded, randomised, controlled study. Gut 2014;63:125-130.

26 Prakash SR, Verma S, McGowan J, Smith BE, Shroff A, Gibson GH, et al: Improving the quality of colonoscopy bowel preparation using an educational video. Can J Gastroenterol 2013;27:696-700.

27 Calderwood AH, Lai EJ, Fix OK, Jacobson BC: An endoscopist-blinded, randomized, controlled trial of a simple visual aid to improve bowel preparation for screening colonoscopy. Gastrointest Endosc 2011;73:307-314.

28 Bucci C, Rotondano G, Hassan C, Rea M, Bianco MA, Cipolletta L, et al: Optimal bowel cleansing for colonoscopy: split the dose! A series of meta-analyses of controlled studies. Gastrointest Endosc 2014;80:566-576 e2.

29 Martel M, Barkun AN, Menard C, Restellini S, Kherad O, Vanasse A: Split-dose preparations are superior to day-before bowel cleansing regimens: a meta-analysis. Gastroenterology 2015;149:79-88.

30 Parmar R, Martel M, Rostom A, Barkun AN: Validated scales for colon cleansing: a systematic review. Am J Gastroenterol 2016;111: 197-204; quiz 205.

31 Guo X, Yang Z, Zhao L, Leung F, Luo H, Kang $X$, et al: Enhanced instructions improve the quality of bowel preparation for colonoscopy: a meta-analysis of randomized controlled trials. Gastrointest Endosc 2016, Epub ahead of print. 